\title{
POTENCIAL CLIMÁTICO PARA A PROLIFERAÇÃO DE DOENÇAS VIRAIS TRANSMITIDAS PELO MOSQUITO AEDES AEGYPTI E OCORRÊNCIAS CONFIRMADAS DE DENGUE EM PORTO ALEGRE/RS - 2014/2015 E 2015/2016
}

\author{
Bianca Marques Maio $^{(a)}$, Erika Collischonn ${ }^{(b)}$, Ricardo Brandolt ${ }^{(c)}$ \\ (a) Programa de Pós-graduação em Geografia, Universidade Federal de Pelotas, biankamaio@ hotmail.com \\ (b) Departamento de Geografia /ICH, Universidade Federal de Pelotas, ecollischonn@ gmail.com

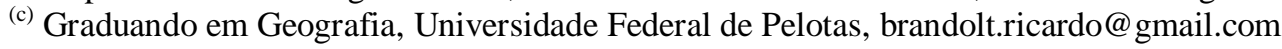

\section{Eixo: Climatologia em diferentes níveis escalares: mudanças e variabilidades}

\begin{abstract}
Resumo/
Neste artigo, apresenta-se o processo de classificação do potencial climático de proliferação do mosquito Aedes aegypti para Porto Alegre/RS e os seus resultados por semana epidemiológica no período mais propício à ocorrência da dengue (dezembro a junho), nos anos 2014/2015 e 2015/2016. Estes dados são confrontados com os casos confirmados de dengue registrados pela Vigilância Sanitária de Porto Alegre, disponibilizados por semana epidemiológica. Esta análise faz parte do estudo referente a relação entre clima e dengue em Porto Alegre que, por sua vez, se integra ao projeto "Clima urbano e dengue nas cidades brasileiras: riscos e cenários em face das mudanças climáticas globais". Este trabalho se organizou em três etapas distintas. A primeira refere-se à aplicação da proposta do Serviço de Alerta Climáticos de Dengue, desenvolvido pelo LABOCLIMA (Laboratório de Climatologia) da UFPR aos recortes temporais propostos, de dezembro de 2014 a junho de 2015 e de dezembro de 2015 a junho de 2016. A segunda refere-se à organização dos dados da dengue por semana epidemiológica. Na última etapa, se analisa conjuntamente os dados no sentido de constatar possíveis relações. Verifica-se relação entre classes de temperatura e a classificação final do risco e ocorrências de dengue para o recorte temporal de 2015/2016, porém, não se observa relação similar no recorte temporal 2014/2015. Daí se conclui que o potencial climático é um fator confluente para a ocorrência de dengue numa cidade no subtrópico, mas a variabilidade dos casos de um ano para o outro, resulta de múltiplos fatores ainda a explorar.
\end{abstract}

Palavras chave: Clima - dengue - Sacdengue

\section{Introdução}

O mosquito transmissor da febre amarela (o mesmo vetor da dengue) foi efetivamente eliminado no Brasil na década de 1960, depois de uma década de intensas campanhas de extermínio. Posteriormente, parece ter ocorrido uma despreocupação quanto ao controle do mosquito, o que fez reemergir a dengue no país nas décadas seguintes até aumentar em progressão desafiadora neste novo milênio, particularmente devido a presença de quatro sorotipos da doença e a proliferação da dengue em todos os estados da nação (MENDONÇA, SOUZA e DUTRA, 2009, p.259). 
Nesta nova fase de disseminação da dengue no Brasil, o crescimento e adensamento urbano, tem contribuído para o aumento dos casos de dengue, visto que o mosquito fêmea precisa de sangue humano durante a gestação e, no ato da picada, pode contrair o vírus de alguém contaminado ou passá-lo para uma pessoa que ainda não foi infectada. O modo de vida urbano, propiciado pelo desenvolvimento de meios de transporte diversos, também ampliou a circulação de pessoas contaminadas entre cidades, estados ou países facilitando a transmissão do vírus.

Estudos recentes têm apontado que o Aedes aegypti está se adaptando a condições climáticas adversas, por exemplo de frio ou estiagem; porém, nas latitudes mais meridionais do Brasil, por enquanto, os casos de dengue autóctone têm um comportamento mais sazonal. Aumentam na condição de tempo mais favorável ao desenvolvimento do vetor (prevalência de temperatura mínima e máxima entre $22^{\circ} \mathrm{C}$ e $30^{\circ} \mathrm{C}$ com chuvas regulares, mas intermitentes), normalmente entre dezembro e abril, e diminuem quando fica mais frio e desfavorável. Além disso, os números totais variam muito de ano para ano e a frequência das ocorrências é variável, mesmo ao longo do período mais favorável. Esta variabilidade tem relação com a reintrodução do vírus ou de novos sorotipos do mesmo, com o grau de vigilância sanitária, tanto por parte do poder público, como da população. Supondo que também possa haver uma relação com a variabilidade climática anual, que potencializa ou não a proliferação do vetor da doença, é que se realiza este trabalho aplicando a metodologia do SACDENGUE/UFPR para Porto Alegre.

Neste artigo, apresenta-se o processo de classificação do potencial climático de proliferação do mosquito Aedes aegypti para Porto Alegre/RS e os seus resultados por semana epidemiológica no período mais propício à ocorrência da dengue (dezembro a junho), nos anos 2014/2015 e 2015/2016. Estes dados são confrontados com os casos confirmados de dengue registrados pela Vigilância Sanitária de Porto Alegre, disponibilizados por semana epidemiológica. Esta análise faz parte do estudo referente a relação entre clima e dengue em Porto Alegre que, por sua vez, se integra ao projeto "CLIMA URBANO E DENGUE NAS CIDADES BRASILEIRAS: RISCOS E CENÁRIOS EM FACE DAS MUDANÇAS CLIMÁTICAS GLOBAIS (Processo CNPQ 404204/2013-9).

\section{Metodologia}

Este trabalho se organizou em três etapas distintas. A primeira refere-se à aplicação da proposta do Serviço de Alerta Climáticos de Dengue, desenvolvido pelo LABOCLIMA (Laboratório de Climatologia) da UFPR aos recortes temporais propostos, de dezembro de 2014 a junho de 2015 e de dezembro de 2015 


\section{OS DESAFIOS DA GEOGRAFIA FÍSICA NA FRONTEIRA DO CONHECIMENTO \\ Instituto de Geociências - Unicamp \\ Campinas - SP \\ 28 de Junho à 02 de Julho de 2017}

a junho de 2016. A segunda refere-se à organização dos dados da dengue por semana epidemiológica. Na última etapa, se analisa conjuntamente os dados no sentido de constatar possíveis relações.

As secretarias de saúde trabalham com a notificação por "semana epidemiológica", que é um recorte temporal padronizado, que permite a comparabilidade dos dados. Elas iniciam-se no domingo e terminam no sábado. A primeira semana epidemiológica de cada ano é aquela que contém o maior número de dias do novo ano. Por isto, elas não coincidem, necessariamente, com o calendário.

A potencialidade do clima na proliferação da dengue em Porto Alegre foi obtida conforme a proposição metodológica do SACDENGUE/UFPR. Esta metodologia permite compreender a distribuição temporal de condições propícias, ou não, para o recorte temporal definido na pesquisa.

Conforme o boletim normativo do LABOCLIMA (Boletim ${ }^{\circ}$ 0), a reprodução e a evolução do mosquito encontram condições ambientais impróprias sob temperaturas acima de $40^{\circ} \mathrm{C}$ e abaixo de $10^{\circ} \mathrm{C}$. Porém, nos estudos relativos à biologia e condições térmicas do Aedes aegypti, provenientes de quatro regiões bioclimáticas da Paraíba, Beserra (apud MENDONÇA, 2011, p. 3) evidenciou que para algumas regiões daquele estado "a amplitude de temperatura favorável ao ciclo de vida das populações de A. aegypti em condições de laboratório encontra-se entre $22^{\circ} \mathrm{C}$ e $30^{\circ} \mathrm{C}$, e que os extremos de temperatura de $18^{\circ} \mathrm{C}$ e $34^{\circ} \mathrm{C}$ apresentaram efeitos negativos sobre o desenvolvimento e a fecundidade do inseto".

Para caracterizar cada situação de risco ao desenvolvimento do vetor nas cidades considerou-se as condições ambientais/meteorológicas conforme a Figura 1.

\begin{tabular}{|c|c|c|c|}
\hline Risco & Faixa de Temperatura & Precipitação & Período \\
\hline Risco Alto & $\begin{array}{l}\text { Prevalência (em horas) de } \\
\text { temperaturas mínimas e } \\
\text { máximas entre } 22^{\circ} \mathrm{C} \text { e } 30^{\circ} \mathrm{C}\end{array}$ & Superior a $10 \mathrm{~mm}$ diários & $\begin{array}{c}72 \text { a } 120 \text { horas (anterior ou } \\
\text { posterior a chuva) }\end{array}$ \\
\hline Risco Médio & $\begin{array}{l}\text { Prevalência (em horas) de } \\
\text { temperaturas mínimas entre } \\
20^{\circ} \mathrm{C} \text { e } 22^{\circ} \mathrm{C} \text { e máximas } \\
\text { entre } 30^{\circ} \mathrm{C} \text { e } 32^{\circ} \mathrm{C} \text {. }\end{array}$ & Superior a $20 \mathrm{~mm}$ diários & $\begin{array}{c}120 \text { a } 168 \text { horas (anterior ou } \\
\text { posterior a chuva) }\end{array}$ \\
\hline Risco Baixo & $\begin{array}{l}\text { Prevalência (em horas) de } \\
\text { temperaturas mínimas entre } \\
18^{\circ} \mathrm{C} \text { e } 20^{\circ} \mathrm{C} \text { e máximas } \\
\text { entre } 32^{\circ} \mathrm{C} \text { e } 34^{\circ} \mathrm{C} \text {. }\end{array}$ & Superior a $30 \mathrm{~mm}$ diários & $\begin{array}{c}\text { Superior a } 168 \text { horas (anterior } \\
\text { ou posterior a chuva) }\end{array}$ \\
\hline Sem Risco & $\begin{array}{l}\text { Prevalência (em horas) de } \\
\text { temperaturas mínimas } \\
\text { inferiores a } 18^{\circ} \mathrm{C} \text { e máximas } \\
\text { superiores a } 34^{\circ} \mathrm{C} \text {. }\end{array}$ & $\begin{array}{c}\text { Precipitação contínua ou } \\
\text { ausência }\end{array}$ & - \\
\hline
\end{tabular}

Figura 1 - Condições Ambientais-meteorológicas de Risco de Dengue.

Fonte: ROSEGHINI, 2013, p. 56. 


\section{OS DESAFIOS DA GEOGRAFIA FÍSICA NA FRONTEIRA DO CONHECIMENTO \\ Instituto de Geociências - Unicamp \\ Campinas - SP \\ 28 de Junho à 02 de Julho de 2017}

Com estas bases foram consideradas condições climáticas de alto risco (predominância das faixas de temperatura entre 22 e $30^{\circ} \mathrm{C}$, precipitação entre 10 e $20 \mathrm{~mm}$ ), médio risco (predominância entre 20 a $22^{\circ} \mathrm{C}$ e 30 e $32^{\circ} \mathrm{C}$, precipitação entre 20 e $30 \mathrm{~mm}$ ), baixo risco (entre 18 e $20^{\circ} \mathrm{C}$ e 32 a $34^{\circ} \mathrm{C}$, precipitação superior a 30mm) e consideradas fora da zona favorável a reprodução do agente transmissor as temperaturas abaixo de $18^{\circ} \mathrm{C}$ e acima de $34^{\circ} \mathrm{C}$ e de precipitação contínua ou inexistente. O período de ocorrência do quadro de temperaturas aliadas a precipitações também foi incluído nas analises, sendo de 3 a 5 dias antes ou depois da precipitação como alto risco, de 5 a 7 dias como médio risco e acima de 7 dias como baixo risco.

Para classificar este potencial climático para proliferação do agente vetor da dengue, foram obtidos os dados horários da estação automática do INMET de Porto Alegre e organizados em planilha Excel. Estes dados meteorológicos foram ajustados ao horário de Brasília (fuso -3) e segmentados de acordo com a semana epidemiológica (7 dias) resultando, depois da aplicação de fórmulas de contagem, em gráficos de participação de cada classe de temperatura definida pelo Sacdengue como mostrado na Figura 2.

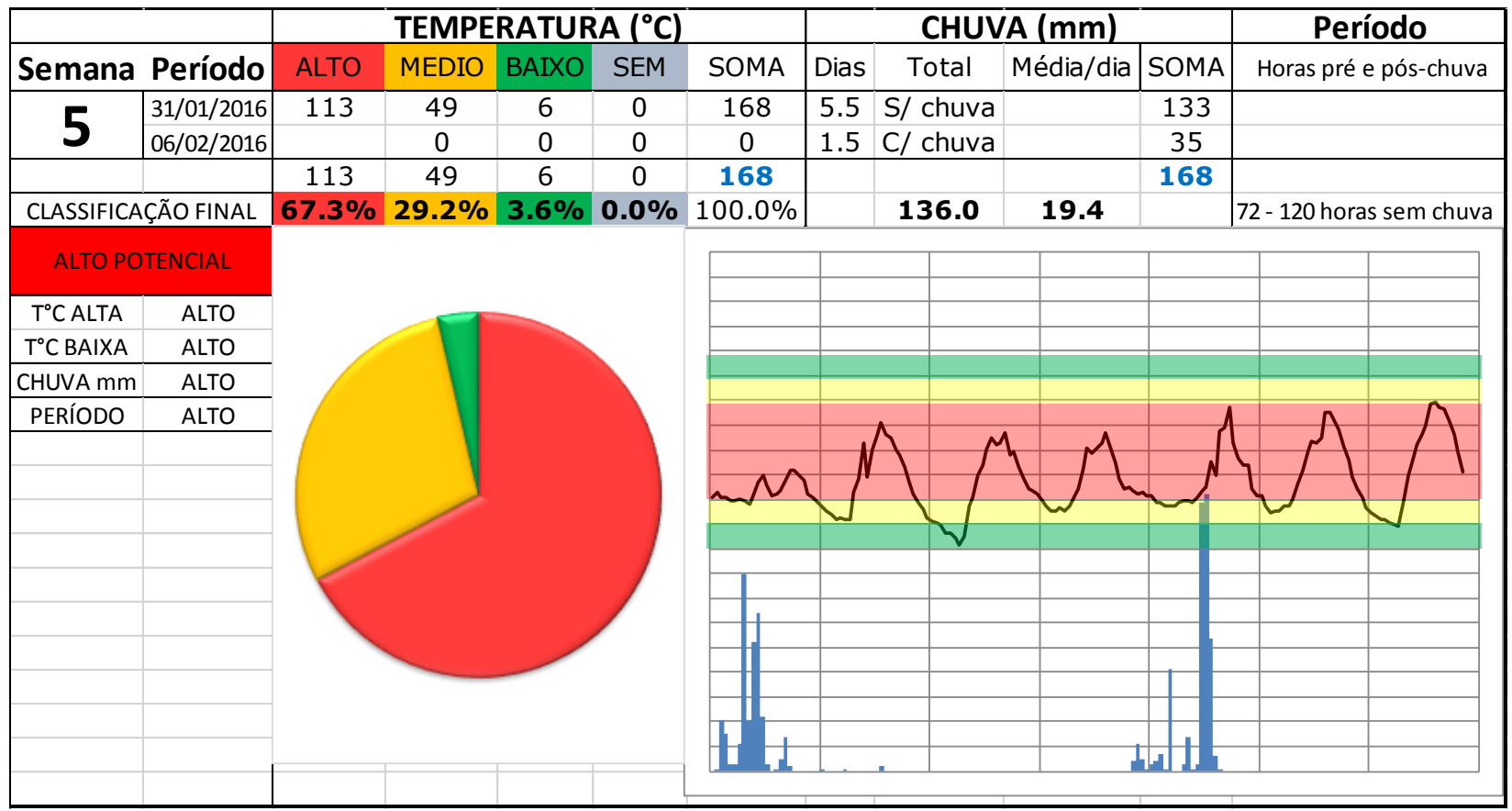

Figura 2 - Tabela de processamento de dados horários para aplicação do SACDENGUE.

Fonte: INMET -Estação automática de Porto Alegre/RS (Organizado por Ricardo Brandolt)

A Principal variável para a determinação do grau de risco neste processo é a temperatura. Na Figura vemos que a interrelação entre planilhas montada em Excel dispõe de células para: identificação da SE; período da SE; cabeçalho com as variáveis em questão (temperatura, chuva e período); contagem das 
medidas térmicas dentro das faixas determinadas; representação percentual das medidas térmicas (em relação ao universo semanal); somatório das medidas (168 medidas a cada SE); proporção em dias com e sem chuva; contagem das ocorrências pluviométricas horárias durante a semana (168); precipitação acumulada na semana; média diária de precipitação; identificação da período pré e pós chuva da SE; classificar o risco quanto à "T ${ }^{\circ} \mathrm{C}$ ALTA", “TC BAIXA”, "CHUVA (mm)” e "PERÍODO” que resultam na "CLASSIFICAÇÃO FINAL" do risco de dengue da SE.

A temperatura foi o principal fator para definir o risco potencial das semanas epidemiológicas, considerando que o ovo pode durar até 500 dias em estado hibernativo até que encontre uma condição propícia para sua eclosão. Dessa forma, se a predominância das temperaturas se encontra entra $40 \%$ e $50 \%$, mas com risco alto no que se refere a média diária de precipitação (entre $10 \mathrm{~mm}$ e $20 \mathrm{~mm}$ ) e o período de 72 a 120 sem chuva, pressupões-se, pela análise conjunta das variáveis meteorológicas, que a semana apresenta alto risco potencial para a proliferação do mosquito.

Os dados confirmados de dengue foram obtidos junto aos boletins epidemiológicos da Vigilância Sanitária da Secretaria de Saúde de Porto Alegre já disponibilizados pelo espaço temporal 'semana epidemiológica'. O ritmo climático local contribui somente para a ocorrência dos casos autóctones, mesmo assim, os casos importados também foram incorporados a análise, considerando que, normalmente, os primeiros casos de dengue em Porto Alegre são os importados; assim, a manifestação dos casos de dengue autóctone ocorre, normalmente, de 10 a 20 dias depois de o vetor ter inoculado sangue com o vírus de alguma pessoa que trouxe a doença de fora. Isto ocorre porque o período de incubação extrínseco, que ocorre no vetor, dura em média dez dias e o intrínseco, que ocorre no ser humano, dura em média de 3 a 7 dias (podendo variar de 1 a 12 dias). Além disso, os casos importados ao longo do período, sempre reintroduzem a possibilidade da transmissão.

Para uma terceira etapa de trabalho foram confrontados os dados confirmados de dengue com o resultado obtido da aplicação do SACDENGUE/UFPR. Normalmente os primeiros casos de dengue em Porto Alegre são os importados

\section{Resultados}

Os meses de verão e outono dos anos de 2014/2015 e 2015/2016 foram diferenciados quanto a variabilidade dada pelo El Niño/Oscilação Sul, enquanto o primeiro período foi de El Niño Neutro, o segundo foi de El Niño forte. 
Durante janeiro de 2014, após o levantamento de vários modelos climáticos, a Organização Meteorológica Mundial advertiu que havia uma possibilidade de um fraco El Niño acontecendo durante 2014. Ao longo daquele ano, porém, a atmosfera não conseguiu responder de modo a reforçar o desenvolvimento de um El Niño e alguns dos indicadores oceânicos de El Niño voltaram aos valores de limiar, devido a um arrefecimento das temperaturas do mar no Pacífico tropical. Assim, o fim de 2014 e início de 2015 foi de condições de El Nino fraco antes tendendo a condições El Niño Oscilação Sul neutro.

Em fevereiro de 2015, novos prognósticos indicaram que as condições de El Niño voltariam a se fortalecer. Em novembro e dezembro de 2015, o Índice oceânico Niño 3,4 da NOAA atingiu um pico de 2,4 ${ }^{\circ} \mathrm{C}$ de anomalia, valor que ultrapassou os índices máximos encontrados no forte El Niño de 1997/1998. A anomalia manteve-se em valores próximos a este até fevereiro de 2015 quando começou a baixar significativamente, porém manteve-se acima do limiar até abril. O evento começou a enfraquecer, com valores de anomalia da temperatura do mar decrescentes em todo o Pacífico Equatorial. Institutos como o NOAA e o IRI declararam que o evento El Niño tinha terminado no final de maio / início de junho de 2016 (NOAA, 2016; IRI 2017).

A resposta a essa variabilidade global do clima, no sul do Brasil se manifesta principalmente no padrão de distribuição da precipitação. Em anos de El Niño forte chove bem mais que a média de setembro até o final do verão. Em Porto Alegre, no período 2014/2015, os valores de temperatura (máxima, média e mínima) foramligeiramente superiores ao da Normal Climatológica (1961-1990) nos meses de dezembro, janeiro, março, abril, maio e junho, enquanto o mês de fevereiro praticamente se igualou a normal. Já, quanto a precipitação os valores ficaram acima dos valores referência nos meses de dezembro, janeiro e junho, enquanto fevereiro, março, abril e maio registraram precipitação inferior à normal (Figura 3).

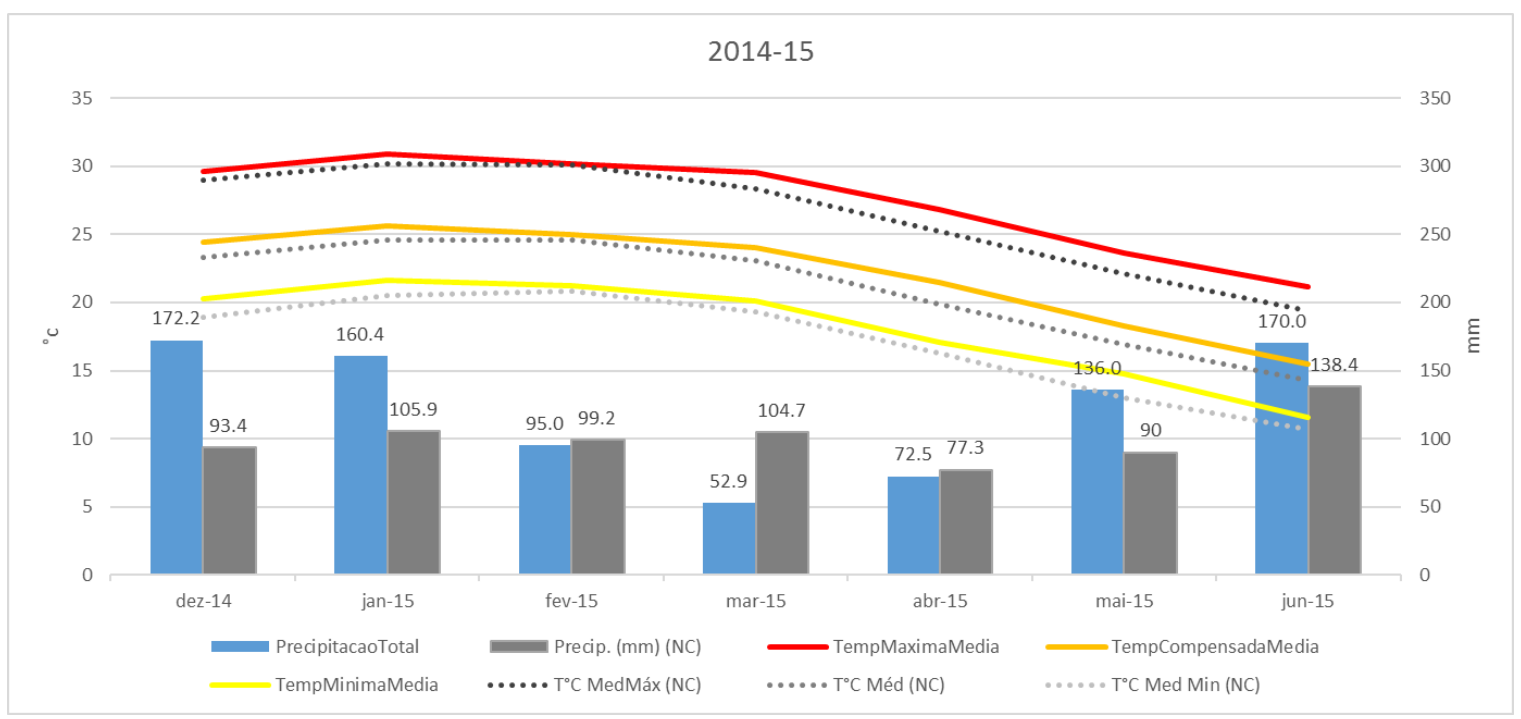


XVII Simpósio Brasileiro de Geografia Fisica Aplicada

I Congresso Nacional de Geografia Física
OS DESAFIOS DA GEOGRAFIA FÍSICA NA FRONTEIRA DO CONHECIMENTO

Instituto de Geociências - Unicamp

Campinas - SP

28 de Junho à 02 de Julho de 2017

Figura 3 - Recorte temporal 2014/2015- Variação dos valores de temperaturas (máxima, média e mínima) e de precipitação mensal em relação às normais climatológicas (1961-1990).

Fonte: INMET (organizado por Ricardo Brandolt).

No período de dezembro de 2015 a junho de 2016 de Porto Alegre (Figura 4), evidencia-se uma inicial semelhança quanto às médias históricas apesar dos valores se encontrarem acima da referência no verão, exceto no mês de março. O mês de abril foi atípico com altas temperaturas, já o mês seguinte maio, foi bem mais frio do que o padrão. Há uma clara ruptura no padrão da temperatura de abril para maio. Quanto a precipitação este período foi bem mais chuvoso que o anterior $(\mathrm{mm})$, os totais mensais foram superiores à normal climatológica de dezembro à abril, sendo que foram mais do que o dobro da normal em março e abril, que normalmente são os meses de menos chuva em Porto Alegre. A partir de abril os valores de precipitação ficaram abaixo da referência (maio e junho).

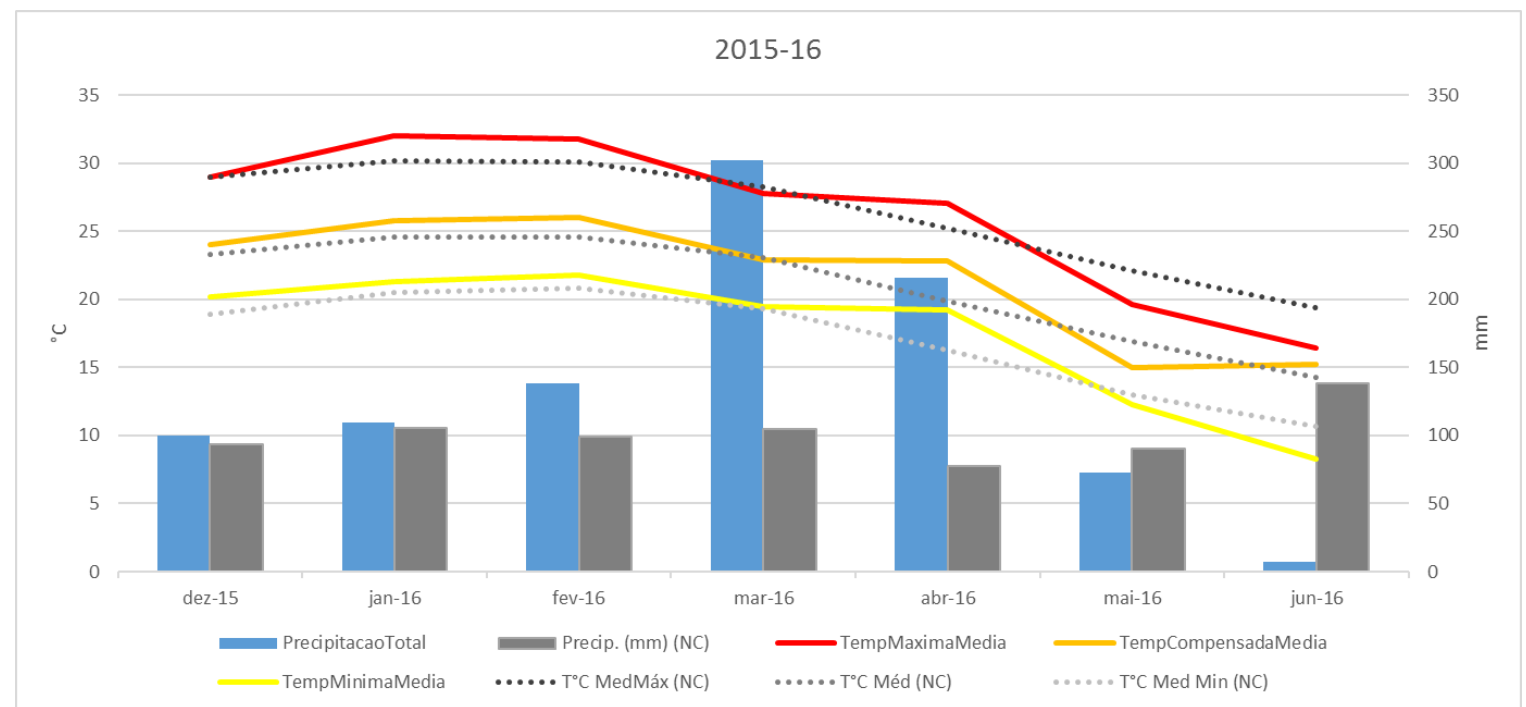

Figura 4- Recorte temporal 2015/2016- Variação dos valores de temperaturas (máxima, média e mínima) e de precipitação mensal em relação às normais climatológicas (1961-1990).

Fonte: INMET (organizado por Ricardo Brandolt).

A aplicação do método Sacdengue aos dados meteorológicos evidenciou uma distribuição das classificações finais de risco de forma análoga à variação do clima da cidade de dezembro a junho para os dois períodos. De modo geral a Tabela 1 mostra que em 2014/2015, 17 semanas epidemiológicas tiveram classificação de alto potencial para a proliferação do mosquito, 04 com médio potencial, 01 com baixo 
potencial e 09 sem potencial de risco. Em 2015/2016, 21 semanas epidemiológicas obtiveram classificação final de alto potencial de risco, 01 com baixo potencial e 09 sem potencial.

Tabela 1 - Distribuição das classificações finais do risco potencial para os períodos analisados.

\begin{tabular}{ccc}
\hline & $2014 / 2015$ & $2015 / 2016$ \\
\hline ALTO POTENCIAL & 17 & 21 \\
MÉDIO POTENCIAL & 4 & 0 \\
BAIXO POTENCIAL & 1 & 1 \\
SEM POTENCIAL & 9 & 9 \\
\hline Total & 31 & 31 \\
\hline
\end{tabular}

Os casos de dengue para os períodos 2014/2015 e 2015/2016 em Porto Alegre revelam um aumento significativo do primeiro para o segundo período analisado; enquanto no período 2014/2015 foram registrados 47 casos importados e 17 casos autóctones, no período 2015/2016 foram registrados 107 casos importados e 316 casos autóctones.

Foram considerados os casos confirmados das cinco últimas semanas epidemiológicas do ano anterior (dezembro) e as vinte e seis semanas do ano seguinte (até final de junho). A figura 6 apresenta a distribuição dos casos autóctones e importados por semana epidemiológica e por período. Enquanto que no primeiro período de 2015, até a semana epidemiológica 20 de ambos os anos, os casos de dengue autóctone apresentam um máximo de 4 casos nas semanas 12 e 18 (22 a 28/03 e 03 a 09/05), no ano de 2016 para o mesmo período se apresentam de 38 e 36 casos nas semanas 11 e 16 (13 a 19/03 e 17 a 23/04), respectivamente. Os casos de dengue importada praticamente dobraram de um ano para o outro, atingindo um máximo de 7 casos na semana 14 (05 a 11/04) e enquanto 2016 apresentaram 11 e 10 casos nas semanas 10 e 17 (06 a 12/03 e 24 a 30/04), respectivamente. 


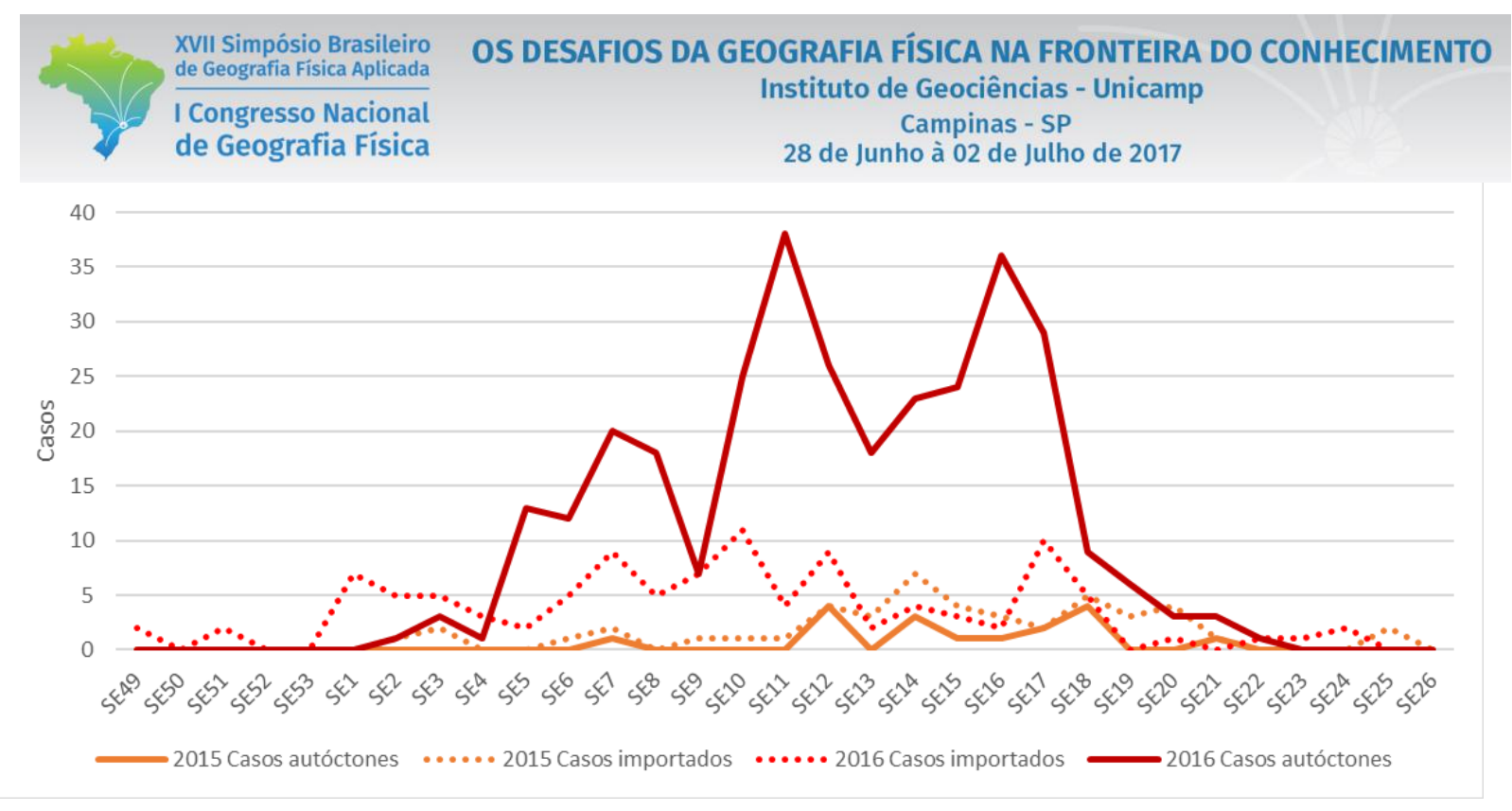

Figura 6 - Distribuição dos casos confirmados de dengue por SE nos anos de 2015 e 2016 até a SE27.

Fonte: Vigilância Sanitária da Prefeitura Municipal de Porto Alegre, 2016 (Organizado por Ricardo Brandolt).

Os casos confirmados de infecção ao longo das semanas em cada período foram confrontados com a representação percentual das medidas térmicas na semana (cores nas colunas de fundo da área do gráfico) e pela classificação final do risco potencial da Semana Epidemiológica indicada na parte superior do gráfico, sobre cada SE. As Figuras 7 e 8 a seguir representam esta análise integrada dos dados referentes aos dois recortes temporais escolhidos. 


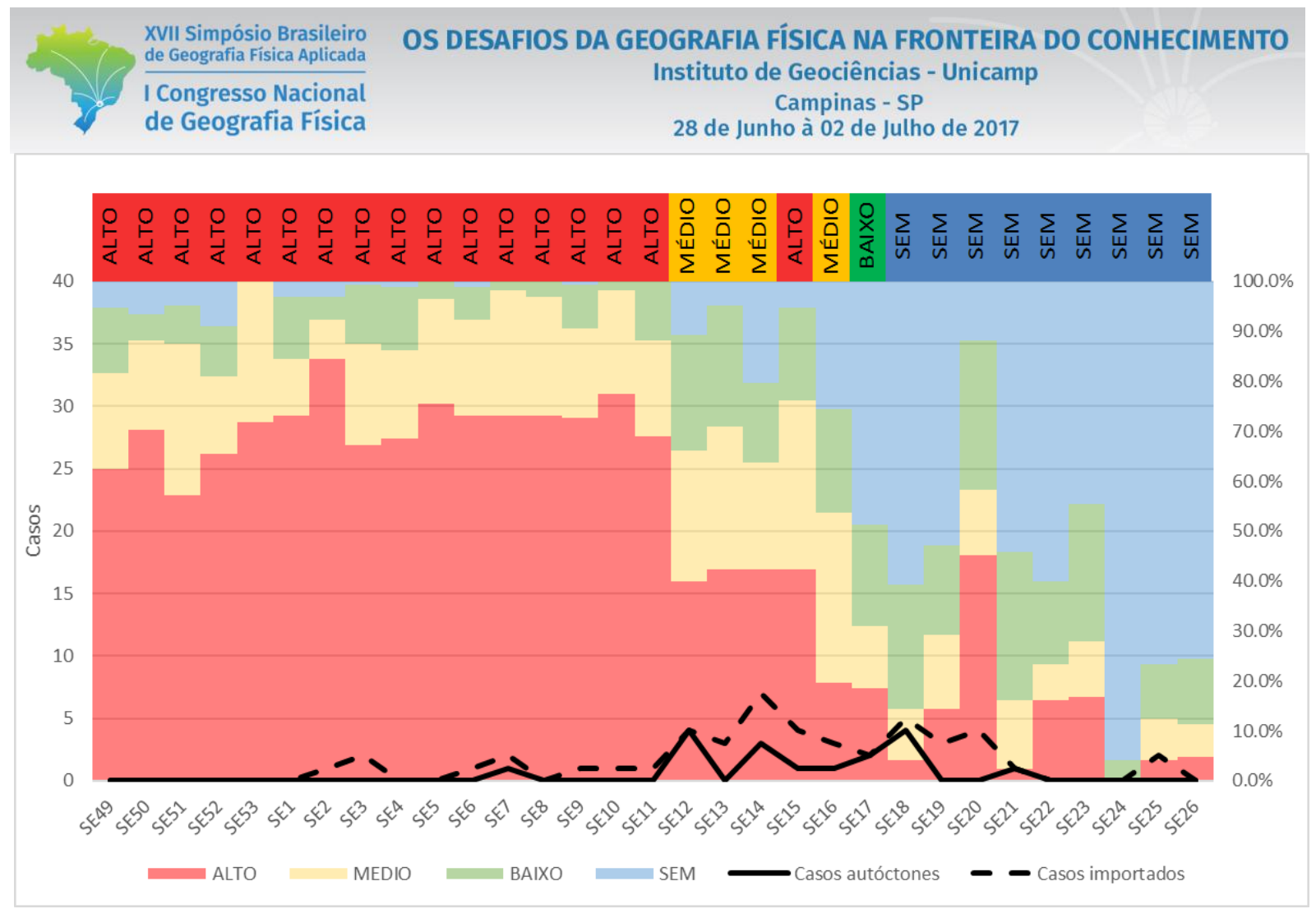

Figura 7 - Gráfico comparativo entre os casos confirmados de dengue de dezembro de 2014 a abril de 2015 , predominâncias das classes de temperatura e a classificação final do risco das semanas epidemiológicas.

No recorte temporal (figura 7), o risco climático manteve-se alto da SE48 de dezembro de 2014 até a semana SE11 de 2015. Já no período seguinte (Figura 8), o risco climático manteve-se alto da SE48 de dezembro de 2015 até a semana SE16 de 2016, ou, seja, por pelo menos um mês a mais. Também já tinha se constatado nas análises das médias mensais de temperatura, que o mês de abril de 2016 foi atipicamente quente. A maioria dos casos de dengue deste período ocorreu, justamente nos meses de março e abril, tanto pelo vírus autóctone que se disseminou, quanto pela reintrodução do vírus por pessoas que passaram suas férias fora da cidade, considerando sempre o período necessário ao ciclo de desenvolvimento do mosquito (em média de 10 a 12 dias). Como pode ser avaliada na análise semanal de Porto Alegre para esse mesmo período, a queda das temperaturas ocorrida no final do mês de abril (SE 17) propiciou a diminuição drástica dos casos de dengue no município, uma semanas depois. 


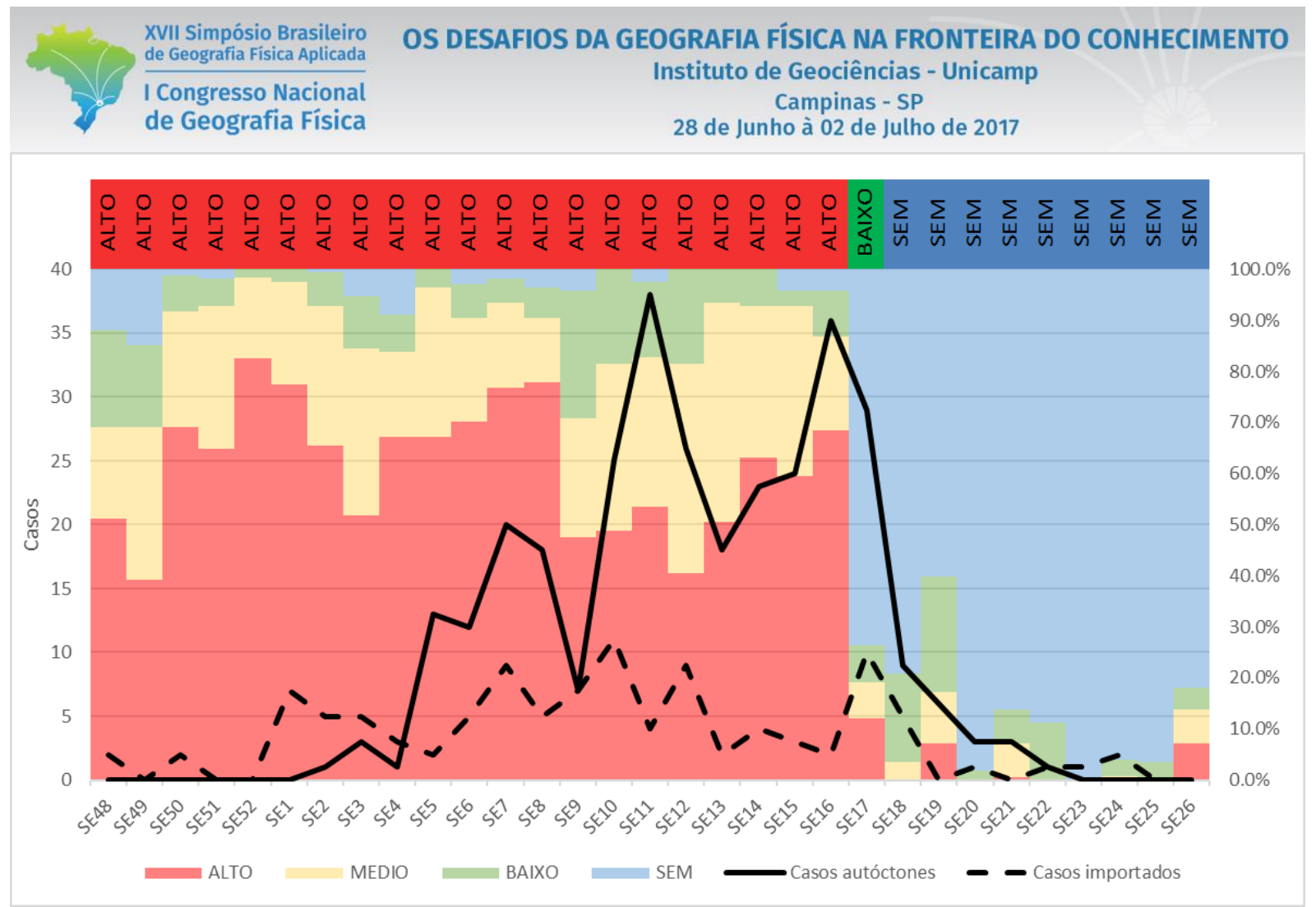

Figura 8 - Gráfico comparativo entre os casos confirmados de dengue de dezembro de 2015 a abril de 2016, predominâncias das classes de temperatura e a classificação final do risco das semanas epidemiológicas.

\section{Conclusões e considerações}

A partir da análise realizada, pode-se fazer considerações a respeito dos períodos completos e por semana epidemiológica. Primeiramente constatou-se que o período 2015/2016 foi bem mais chuvoso do que o período anterior, condição que demonstrou-se estar relacionada ao forte El Niño então ocorrido. Além disso, enquanto no recorte temporal de 2014/2015 foram constatadas 17 semanas de alto potencial para a proliferação do vetor, no período seguinte este número se elevou para 21 semanas. Da mesma forma, os casos de dengue, tanto os importados como os autóctones foram bem superiores no período 2015/2016.

Quanto à distribuição semanal dos casos importados, no primeiro período as ocorrências só começaram em meados de janeiro e tiveram seu auge na semana 14 com 07 casos, enquanto no ano seguinte já estavam ocorrendo desde dezembro. Os casos importados, bem mais frequentes no segundo período, com certeza também reintrioduziram o vírus na cidade de tal forma que possibilitaram um bem maior número de casos autóctones.

Os casos autóctones do primeiro período, que somaram 17 ocorrências, concentraram-se principalmente, entre as semanas 12 e 18. Já no segundo período, que teve um total de 316 ocorrências, houve uma maior 


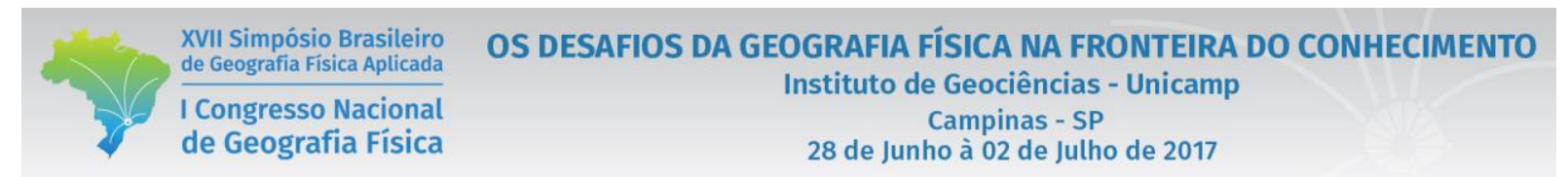

dispersão ao longo do período, com uma intensificação a partir da semana 04 e três picos de occorrência nas semanas 07,11 e 16 com, respectivamente, 20, 38 e 36 casos.

A relação que se constatou entre classes de temperatura e a classificação final do risco e ocorrências de dengue por semana epidemiológica para o segundo recorte temporal (2015/2016), não se observa com a mesma correspondência para o recorte temporal 2014/2015. Claro está que o clima não é o único fator que concorre para a ocorrência de dengue, no entanto, outras características do clima (massas de ar, tipos de tempo, velocidade do vento) na sua sua sucessão temporal por semana epidemiológica precisam ainda ser melhor explorados.

\section{Bibliografia}

INMET- INSTITUTO NACIONAL DE METEOROLOGIA. Bdmet- dados históricos. Disponível em: <http://www.inmet.gov.br/portal/>. Acesso em: 01 mar. 2017.

INMET- INSTITUTO NACIONAL DE METEOROLOGIA. Estações Automáticas. Disponível em: < http://www.inmet.gov.br/portal/index.php?r=estacoes/estacoesAutomaticas/>. Acesso em: 01 mar. 2017.

INMET- INSTITUTO NACIONAL DE METEOROLOGIA. Normais Climatológicas do Brasil 1961-1990. Disponível em: < http://www.inmet.gov.br/portal/index.php?r=clima/normaisclimatologicas/>. Acesso em: 01 mar. 2017.

IRI/Earth Institute/Columbia University. ENSO Resources. Disponível em <http://iri.columbia.edu/ourexpertise/climate/enso/>. Acesso em 10 Mar. 2017

MENDONÇA, Francisco A.; Souza, Adilson V.; DUTRA, Denecir A. Saúde pública, urbanização e dengue no Brasil. In: Sociedade e Natureza (Online) vol.21 no.3 Uberlândia, Dec. 2009. Diponível em < http://www.scielo.br/scielo.php?script=sci_arttext\&pid=S1982-45132009000300003> Acesso em 20 Mar 2017.

PMPA/SMS/ BOLETIIM SEMANAL CGVS. Dados dengue, zika, chikungunya 2016 - se 01 a se 52 . Disponível em: <http://www.ondeestaoaedes.com.br/default.php?reg=23\&p_secao=41>. Acesso em: 05 mar. 2017.

ROSEGHINI, W. F. Clima urbano e dengue no centro-sudoeste do Brasil. Tese de Doutorado em Geografia/UFPR. Curitiba: UFPR; 2013.

LABOCLIMA/UFPR. SACDENGUE - Serviço de Alerta Climático de Dengue. Disponível em < http://www.laboclima.ufpr.br/dengue.htm> Acesso em 26 Fev. 2014.

NOAA/ UNITED STATES DEPARTMENT OF COMMERCE National Centers for Environmental Information.

Equatorial Pacific Sea Surface Temperatures, 2017. Disponível em
<https://www.ncdc.noaa.gov/teleconnections/enso/indicators/sst.php > Acesso em 26 Fev. 2014

NOAA/ UNITED STATES DEPARTMENT OF COMMERCE. El Niño theme page. How the failed 2014-15 El Nino fueled the strong 2015-16 El Nino (18 May,2016). Disponível em < https://www.pmel.noaa.gov/elnino/newsstory/how-failed-2014-15-el-nino-fueled-strong-2015-16-el-nino > Acesso em 10 Mar. 2017.

UFPR-LABOCLIMA / SIMEPAR/ SESA/PR. Dengue - Serviço de alerta climaticometeorológico (SACDENGUE) - Boletim climático informativo, $\mathrm{N}^{\circ}$. 00/2011. 11p. 